\title{
Epidemiological study of hospitalized road traffic injuries in Iran 2011
}

\author{
Rasoul Shavaleh ${ }^{1}$, Seyed Abbas Motevalian*1, Nader Mahdavi ${ }^{1}$, Mashyaneh Haddadi ${ }^{2}$, \\ Mahmoud Reza Mohaghegh ${ }^{3}$, Zahra Hamedi ${ }^{4}$
}

\begin{abstract}
Background: In Iran, Road Traffic Injuries (RTIs) is the second-leading cause of deaths, and the first leading cause of disabilityadjusted life year, and has one of the highest rates of death (32.1 per 100000 population) all over the world. This study's aim was to investigate the epidemiological pattern and underlying components of hospitalized RTIs in 31 provinces of Iran in 2011.

Methods: This study conducted on all hospitalized RTIs during one-year period (March 21, 2011 to March 21, 2012). Data extracted from a hospital-based traffic injury registration system. According to a national law passed in 2005, all hospital expenses of traffic injuries should be covered by ministry of health based on governmental tariffs. The medical costs of eligible patients will be paid to the hospitals only if the patient data are sent to the above mentioned database. Statistical analysis was performed using SPSS v.16 (SPSS Inc., Chicago, USA), and spatial maps are provided using GIS 10.2. Descriptive statistics and t-test were used to compare means. World (WHO 2000-2025) standard population used to calculate age-adjusted incidence rate. All statistical tests were performed at the $5 \%$ level of statistical significance.

Results: There were 322,064 injured cases recorded in the registration system during the study period. The national age-adjusted incidence rate of RTIs was 405 per 100,000 population. The highest incidence rates were in the age group of 15-29 years (643 per 100,000 population), followed by $30-44$ year age groups (401 per 100,000 population). The incidence rate in men was 3.36 times more than women. Motorcyclist were the most frequent type of road users (39.2\%) who involved in RTIs, followed by passengers (28.9\%) and pedestrians $(20.0 \%)$. Head injuries were among the most affected part of the body which occurred in $27.2 \%$ of the patients. The proportion of urban crashes was $60.7 \%$.

Conclusion: The results of this study indicated that the majority of RTI occurred on motorcyclists and head injuries was the most commonly affected body part. Therefore, in order to reduce motorcycle accidents and avoiding head injury among them, stricter law enforcement is urgently needed for helmet use and promotion of safety behaviors among motorcycle riders.
\end{abstract}

Keywords: Road traffic injuries, Road user, Head injury

Copyright@ Iran University of Medical Sciences

Cite this article as: Shavaleh R, Motevalian SA, Mahdavi N, Haddadi M, Mohaghegh MR, Hamedi Z. Epidemiological study of hospitalized road traffic injuries in Iran 2011. Med J Islam Repub Iran. 2018(17 June);32:50. https://doi.org/10.14196/mjiri.32.50

\section{Introduction}

Road traffic crashes (RTCs) are the leading cause of death, with an increasing number occurring in developing countries. It is estimated that nearly 1.27 million people die each year as a result of road traffic crashes, and 50 million people are injured worldwide, and is shown to

Corresponding author: Dr Seyed Abbas Motevalian, motevalian.a@iums.ac.ir

1. Department of Epidemiology, School of Public Health, Iran University of Medical Sciences, Tehran, Iran.

2. Injury Prevention \& Safety Promotion Department, Disaster \& Emergency Management Center, Ministry of Health \& Medical Education, Tehran, Iran.

3. Anesthesia and Critical Care Department, Hasheminejad Kidney Center, School of

Medicine, Iran University of Medical Sciences, Tehran, Iran.

4. Shahid Beheshti University of Medical Sciences, Tehran, Iran. have a huge impact on overall health and development (1). Road crashes are the leading cause of death in young people aged 15-29 years, and bleeds away up to $3 \%$ of global GDP per year (1). However, it has been anticipated that if the present trend of road traffic injuries (RTIs) continues

$\uparrow$ What is "already known” in this topic:

Road Traffic Crashes (RTCs) occur with different distribution in sex, age, type of road user, season, and geography. In Iran, previous studies has shown, Road Traffic Crashes are the second-leading case of death and has one of the highest rate in the world.

$\rightarrow$ What this article adds:

The results of this study indicated that the majority of RTCs were men, motorcyclists, and had age 15-29 and head injury was the most commonly affected body region by RTCs. Urban crashes occur much more frequently and most of the occurs in the summer months, especially during the month of September. 
without drastic intervention, it will become the fifthleading cause of mortality around the world by 2030 (2, 3 ). Many studies have shown an increasing trend of death caused by RTIs in Africa, Eastern Mediterranean and Asia over the recent years $(4,5)$. The Eastern Mediterranean Region (EMR) has the second-highest traffic-related death rates in the whole world (6) and Iran is shown to have the highest rate of RTIs among EMR countries (7, 8).

In Iran, RTIs is the second-leading cause of deaths, and the first leading cause of lost disability-adjusted life year, and has one of the highest rates of death (32.1 per 100000 population) all over the world $(1,9)$. Moreover, it is estimated that RTIs costs can consumes up to $6.46 \%$ of the gross national product (US\$39billion) per year in developing countries such as Iran (10).

The present study was conducted to investigate the epidemiological pattern and underlying components of hospitalized RTIs in 31 provinces of Iran.

\section{Methods}

This study conducted on all hospitalized victims that injured in RTCs during one-year period (March 21, 2011 to March 21, 2012).

From 2005, according to the executive guidelines of Article 92 of the Fourth Economic, Social and Cultural Development Plan in the country, all public, governmental and private hospitals are obliged to admit all inpatients and outpatients who have been injured due to RTCs and provide free-of-charge treatment for injuries The cost of treatment services is funded by using 10 percent of thirdparty car insurance that was deposited into to the special income account belong to the Ministry of Health and Medical Education (11).
Given the law mentioned above, the required data were collected by a trained group of physicians and nurses. Collected information by hospitals was submitted to deputy of health from all provinces for each year.

The database consisted of full name, age, gender, region, type of vehicle (pedestrian, bicycle, motorcycle, and car), place of crashes, date , treatment outcome, and type of injuries were determined based on the International Classification of Diseases (ICD 10), and traffic crashes were classified under V01-V99 codes among people involved in road traffic crashes.

Statistical analysis was performed using SPSS 16 (SPSS Inc., Chicago, USA), and spatial maps are provided using GIS 10.2. Descriptive statistics such as frequency, percentage, mean and standard deviation were used and t-test used to compare means. All statistical tests were performed at the $5 \%$ level of statistical significance. Incidence rates were calculated per 100000 population based on 2010 census. In addition, world (WHO 2000-2025) standard population used to calculate age-adjusted incidence rate (12).

\section{Results}

In Total, 322064 crashes recorded in the data registration system during the study period, in which 321330 (98.8\%) were injured and $3738(1.2 \%)$ death cases. Also, $249175(77.4 \%)$ of accident involved men and the rest 72889 (22.6\%) were women. The average age of entire population was $30.6 \pm 16.9$, and in which the age for men was $(29.94 \pm 16.34)$ and women $(32.44 \pm 18.56)$ with significant different between them $(\mathrm{p}<0.001)$.

The highest crude incident rate of RTIs occurred in the 15-29 year age group, followed by the 30-44 year age group (Table 1). In addition, age-adjusted incidence rate

Table 1. The age and sex-specific incidence rate of hospitalized RTIs in Iran-2011

\begin{tabular}{lccc}
\hline Variables & Number of injuries & Percent & Incidence rate (per 100,000 population) \\
\hline Sex & & & \\
female & 72889 & 22.6 & 195.8 \\
male & 249175 & 77.4 & 657.9 \\
Age -group & & & 207.2 \\
$0-4$ & 12914 & 4 & 215.1 \\
$5-14$ & 24368 & 7.6 & 642.9 \\
$15-29$ & 152322 & 47.4 & 401.3 \\
$30-44$ & 70030 & 21.8 & 369.9 \\
$45-59$ & 37866 & 11.8 & 386.9 \\
$60+$ & 23830 & 7.4 & 38 \\
\hline
\end{tabular}

Table 2. Injured body regions of patients hospitalized due to RTIs in Iran-2011

\begin{tabular}{|c|c|c|}
\hline Injuries to body regions & $\begin{array}{l}\text { Number of hospitalization based } \\
\text { on Injuries to body regions }\end{array}$ & $\begin{array}{c}\text { Percent } \\
\text { of hospitalization based on Injuries } \\
\text { to body regions }\end{array}$ \\
\hline Injuries to the head(S00-S09) & 87492 & 27.2 \\
\hline Injuries to the neck(S10-S19) & 6403 & 2.0 \\
\hline Injuries to the thorax(S20-S29) & 9571 & 3.0 \\
\hline Injuries to the abdomen, lower back, lumbar spine and pelvis(S30-S39) & 20049 & 6.2 \\
\hline Injuries to the shoulder and upper arm(S40-S49) & 13682 & 4.2 \\
\hline Injuries to the elbow and forearm(S50-S59) & 14508 & 4.5 \\
\hline Injuries to the wrist and hand(S60-S69) & 15013 & 4.7 \\
\hline Injuries to the hip and thigh(S70-S79) & 14647 & 4.5 \\
\hline Injuries to the knee and lower leg(S80-S89) & 45104 & 14.0 \\
\hline Injuries to the ankle and foot(S90-S99) & 21511 & 6.7 \\
\hline Injuries involving multiple body regions(T00-T07) & 52687 & 16.4 \\
\hline Others & 12264 & 3.8 \\
\hline Unspecified & 9133 & 2.8 \\
\hline
\end{tabular}




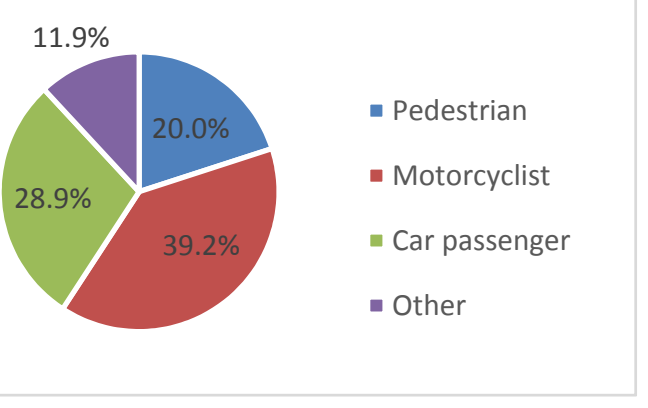

Fig. 2. Road users of road traffic crashes in Iran 2011

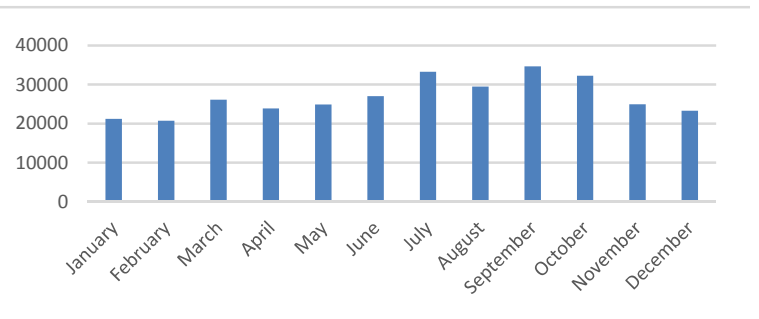

Fig. 3. Monthly Road traffic injuries in Iran 2011

for all population was 404.7 per 100000 population. This rate for males and females was 613.4 and 193.5 per 100000 populations respectively.

The motorcycle crashes $126360(39.2 \%)$ reserved the highest rank in terms of the type of crashes (Road user) and their frequency, Car passengers 92947 (28.9\%), pedestrian crashes $64282(20.0 \%)$ and other $38475(11.9 \%)$ were allocated in the subsequent rank (Fig. 1).

The maximum number of RTIs was observed in September $(34673 ; 10.8 \%)$ and the lowest number occurred in

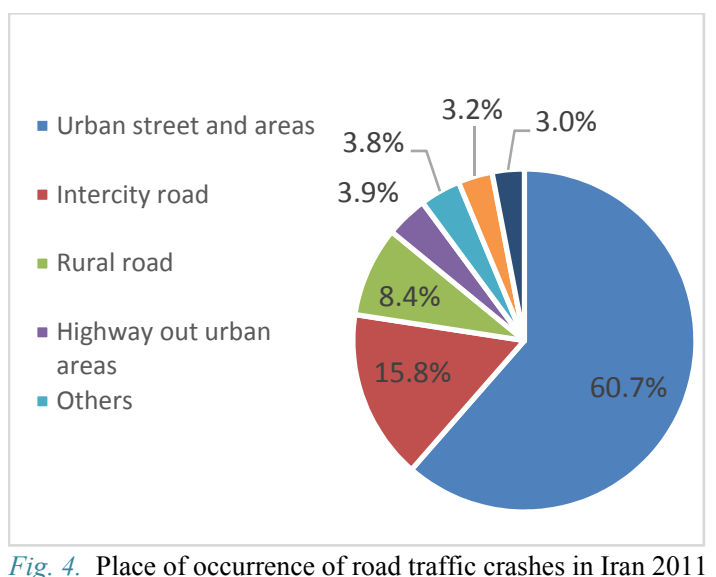

the February (20736; 6.4\%) (Fig. 2).

Analysis of hospitalized RTIs showed that head injuries (S00-S09) 87492(27.2\%), multiple body regions injuries (T00-T07) 52687(16.4\%), and knee and lower leg injuries (S80-S89) 45104(14\%), were the most affected part of the body (Table 2).

In general, urban crashes occur more frequently than rural crashes and other places (Fig. 3).

According to Fig. 4, road traffic accidents had high incidence rate in the central and eastern provinces of Iran, especially in Semnan (1352 cases in 100,000), and Qom provinces (1438 cases in 100,000).

\section{Discussion}

In the present study about three-fourths of RTIs were male patients. This finding is similar to the previous studies in Iran (13), and Colombia (14) . Also, the male: fe-

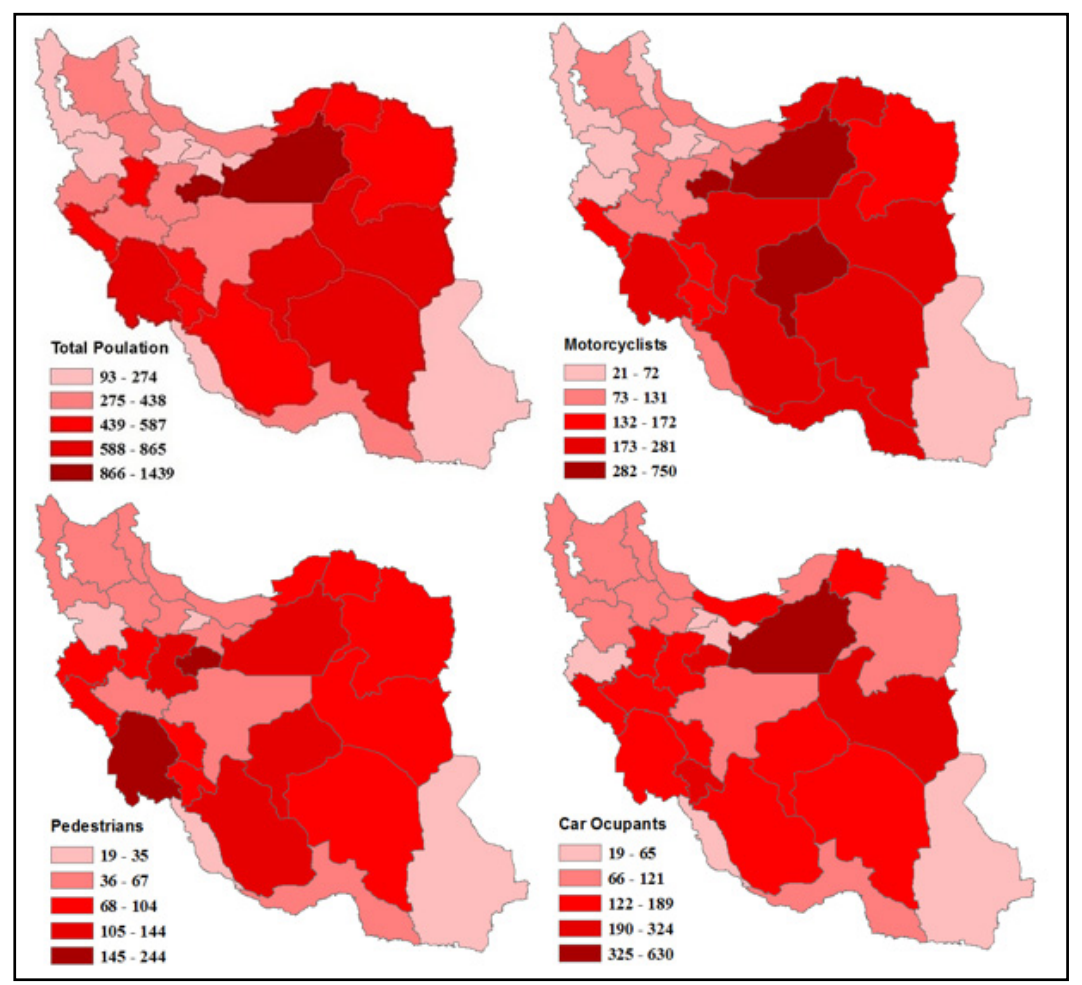

Fig. 1. Geographical distribution map of the incidence rate of road traffic injuries per 100,000 population by road users Iran 2011 


\begin{tabular}{lcc} 
Table 3. Percentage of using helmets according to Global Status Report on Road Safety 2015 (1) \\
\hline Countries & Riders (\%) & Passengers (\%) \\
\hline Indonesia & 85 & 52 \\
Malaysia & 97 & 89 \\
Thailand & 52 & 20 \\
Vietnam & 96 & 83 \\
France & 98 & 92 \\
Norway & 99 & 99 \\
Spain & 99 & 99 \\
Germany & 99 & 99 \\
USA & 63 & 46 \\
Canada & 95 & 95
\end{tabular}

male ratio in our study was 3.42 . While this is consistent with Khorshidi's findings, other studies in the USA, and Nigeria showed male to female ratio less than our study $(15,16)$. The relatively higher ratio of RTIs among young male adults can be explained by differences in attitude, social status, education, occupation, daily household activities, recreation and other cultural factors. Also, women are less involved in the community activities and mostly remain indoor, whereas men are more frequently exposed to high risk behaviors and unsafe road practices (17).

Our study showed that mean age of the victims was $(30.6 \pm 16.9)$ years. Maximum numbers of victims (47.4\%) were between 15-29 years of age followed by age group of 30 - 44 years $(21.8 \%)$. Similar results have been reported from WHO indicating that, nearly $60 \%$ of road traffic deaths occur in individuals between 15 and 44 years old (1). Also, Prior studies in Iran and other countries have found similar results $(1,13,14)$. These findings indicate that people in the most active reproductive age group are more likely to be involved in RTAs, with the enormous economic costs to the society.

The present study revealed that similar to other studies in Iran as well as other developing countries, motorcyclists were responsible for the largest percentage of hospitalized patients $(36 \%)$. This finding is in line with the study conducted in Colombia(14). This is due to higher number of motorcycles in Iran in comparison to other countries in the EMR region (1), and disobeying traffic rules by most motorcycle riders, riding without proper licensing, and avoiding helmet (18). Hence to reduce frequency of motorcycle crashes, enforcement of strict laws and surveillances on helmet use and motorcycle drivers' license recommended.

The most commonly affected body region by RTIs was injuries to the head $(27.2 \%)$. Similar results have been reported in other countries $(19,20)$. Wearing helmets can decrease up to $70 \%$ risk factors for death and $40 \%$ of severe injury. Nevertheless many studies have shown that percentage of helmets user among motorcycle drivers and passengers is very low in Iran (1). According to, WHO's Global Status Report on Road Safety 2015 only 35\% of riders and $12 \%$ of motorcycle -passengers used helmets. On the contrary, these percentages in some Southeast Asian countries, Europe and North America were very higher (Table 3) (1). Strong enforcement of motorcycle helmet law as an effective traffic safety procedure can increase helmet use and subsequently reduce head injuries.
The distribution of crashes by month have shown to be varied, with the highest rate in September and July, and lowest rate in June. While in USA, similar to our study, most accidents occurs in the summer months and October (21), the majority of traffic crashes in Colombia occurs in the fall and winter months (22). Although many factors are associated with road traffic injuries, but the main attributed factor is probably different travel patterns over a year. The main related factors for increased crash rates during summer are length of day, good weather condition, long drives, and increasing speed peak $(23,24)$. Moreover, in Iran, more people tend to take their vacations in summer times which increases RTCs rate.

This study revealed significant findings regarding location of RTIs. The majority of persons injured in road vehicle traffic crashes consisted of urban crashes which is in line with other study in Iran(13). Semnan and Qom had the higher incidence rate within all provinces, because these provinces located in central Iran, and their roads and highways are heavily used by road users.

Limitation of this study was fact that data only involved hospitalized patients and did not include information about victims who died on scene and were not hospitalized. According to this limitation, underestimation in our study should be considered.

\section{Conclusion}

The results of this study indicated that the majority of RTCs were involved the motorcyclists compared to others. Head injury was the most commonly affected body region by RTCs. In general, urban crashes occur much more frequently than rural and other place. In order to reduce motorcycle crashes and head injury it is recommended to enforce stricter laws enforcement, require proper motorcycle drivers' license and helmet use, promote safe behaviors among motorcycle riders and their passengers.

\section{Conflict of Interests}

The authors declare that they have no competing interests.

\section{References}

1. World Health Organization. Global Status Report on Road Safety 2015 2015. Available from: http://www.who.int/violence_injury_ prevention/road safety status/2015/en/.

2. Naeem Z. Road Traffic Injuries-Changing Trend? Int J Health Sci. 2010;4(2).

3. World Health Organization. Global status report on road safety: time for action: World Health Organization; 2009.

4. Nielsen K, Mock C, Joshipura M, Rubiano AM, Zakariah A, Rivara F. 
Assessment of the status of prehospital care in 13 low-and middleincome countries. Prehosp Emerg Care. 2012;16(3):381-9.

5. World Health Organization. Iran (Islamic Republic of) country profile. Geneva: World Health Organization; 2015 [cited 14 August 2014]. Available from: http://www.who.int/countries/irn/en/.

6. Awadhalla MS, Asokan GV, Matooq A, Kirubakaran R. Declining trends in injuries and ambulance calls for road traffic crashes in Bahrain post new traffic laws of 2015. J Epidemiol Glob Health. 2016;6(2):59-65.

7. World Health Organization. The work of WHO in the Eastern Mediterranean Region: Annual report of the Regional Director 1 January-31 December 2013. 2013. Available from: http://www.emro.who.int/annual-report/2013/index.html.

8. Soori H, Hussain S, Razzak JA. Road Safety in the Eastern Mediterranean Region-findings from the Global Road Safety Status Report. East. Mediterr. Health J. 2011;17(10):770-6.

9. Naghavi M, Abolhassani F, Pourmalek F, Lakeh MM, Jafari N, Vaseghi S, et al. The burden of disease and injury in Iran 2003. Popul Health Metr. 2009;7(1):1.

10. Ainy E, Soori H, Ganjali M, Le H, Baghfalaki T. Estimating cost of road traffic injuries in Iran using willingness to pay (WTP) method. PLoS ONE. 2014;9(12):e112721.

11. Dadkhah A, Saied-Moallemi Z, Alem-Rajabi MS. Head and face injuries and helmet use among injured motorcyclists with road accidents in Isfahan, Iran. 2015. 2015:7.

12. Rodrigues EM, Villaveces A, Sanhueza A, Escamilla-Cejudo JA Trends in fatal motorcycle injuries in the Americas, 1998-2010. Int J Inj Contr Saf Promot. 2014;21(2):170-80.

13. Khorshidi A, Ainy E, Soori H, Sabbagh MM. Iranian road traffic injury project: assessment of road traffic injuries in Iran in 2012. J Pak Med Assoc. 2016;66(5):517-20.

14. Rodríguez JM, Peñaloza RE, Montoya JM. Road Traffic Injury Trends in the City of Valledupar, Colombia. A Time Series Study from 2008 to 2012. PLoS ONE. 2015;10(12):e0144002.

15. Rus Ma D, Peek-Asa C, Baragan EA, Chereches RM, Mocean F. Epidemiology of Road Traffic Injuries Treated in a Large Romanian Emergency Department in Tîrgu-Mureş Between 2009 and 2010. Traffic Inj Prev. 2015;16(8):835-41.

16. Madubueze CC, Chukwu COO, Omoke NI, Oyakhilome OP, Ozo C. Road traffic injuries as seen in a Nigerian teaching hospital. Int Orthop. 2011;35(5):743-6.

17. Bahadorimonfared A, Soori H, Mehrabi Y, Delpisheh A, Esmaili A, Salehi M, et al. Trends of fatal road traffic injuries in Iran (20042011). PLoS ONE. 2013;8(5):e65198.

18. Sharma B. Road traffic injuries: a major global public health crisis. Public Health. 2008;122(12):1399-406.

19. Weijermars W, Bos N, Stipdonk HL. Serious road injuries in the Netherlands dissected. Traffic Inj Prev. 2016;17(1):73-9.

20. Getachew S, Ali E, Tayler-Smith K, Hedt-Gauthier B, Silkondez W, Abebe D, et al. The burden of road traffic injuries in an emergency department in Addis Ababa, Ethiopia. Public Health Action. 2016;6(2):66-71.

21. Williams AF, West BA, Shults RA. Fatal crashes of 16-to 17-yearold drivers involving alcohol, nighttime driving, and passengers. Traffic Inj Prev. 2012;13(1):1-6.

22. Rodríguez JM, Peñaloza RE, Montoya JM. Road Traffic Injury Trends in the City of Valledupar, Colombia. A Time Series Study from 2008 to 2012. PLoS ONE. 2015;10(12):e0144002.

23. Anowar S, Yasmin S, Tay R. Comparison of crashes during public holidays and regular weekends. Accid Anal Prev. 2013;51:93-7.

24. Sivak M. During which month is it riskiest to drive in the United States? Traffic Inj Prev. 2009;10(4):348-9. 